\title{
Complete Home Smoking Ban Survey Analysis: An Opportunity to Improve Health Equity Among Sexual Minority Adults in California, USA
}

Marie Boman-Davis ( $\square$ mariebd@ori.org )

Oregon Research Institute https://orcid.org/0000-0002-3781-0096

Veronica L. Irvin

Oregon State University

Erika Westling

Oregon Research Institute

Short report

Keywords: Health Disparities, Policy, Survey Research

Posted Date: August 13th, 2021

DOI: https://doi.org/10.21203/rs.3.rs-789575/v1

License: (c) (i) This work is licensed under a Creative Commons Attribution 4.0 International License.

Read Full License

Version of Record: A version of this preprint was published at BMC Public Health on March 18th, 2022. See the published version at https://doi.org/10.1186/s12889-022-12891-w. 
Complete Home Smoking Ban Survey Analysis: An Opportunity to Improve Health Equity among Sexual Minority Adults in California, USA

Marie C. Boman-Davis, PhD, MPH, MCHES ${ }^{1}$, Veronica L. Irvin, PhD, $\mathrm{MPH}^{2}$, Erika Westling, $\mathrm{PhD}^{1}$

June 27, 2021

${ }^{1}$ Oregon Research Institute, Eugene, OR

${ }^{2}$ Oregon State University, College of Public Health and Human Sciences, School of Social and Behavioral Health Sciences, Corvallis, OR

Corresponding Author: Marie C. Boman-Davis, 1776 Millrace Dr. Eugene, OR 97403, (541) 484-2123 (Office), (541) 484-1108 (Fax), marieb@ori.org 


\begin{abstract}
Introduction: Increasing the proportion of adults living in smoke-free homes is a US Healthy People 2020 objective. Complete home smoking bans are associated with higher odds of smoking cessation attempts and cessation duration. Sexual minority adults have disproportionality higher rates of smoking. This study investigates correlates of having a complete home smoking ban among sexual minority adults in California.
\end{abstract}

Methods: Secondary data analyses of the California Behavioral Risk Factor Surveillance System (CA BRFSS), 2014-2016. The CA BRFSS telephone survey of adults was conducted in English and Spanish and used random digit dial for landline and cell numbers. Weighted descriptive, bivariate, and multivariable logistic regression analyses were stratified by sexual orientation and biological sex.

Results: Sexual minority adults in California had a lower prevalence of complete home smoking bans (Female 76.2\%; Male 75.7\%), higher prevalence of current cigarette smoking (Female 23.3\%; Male 17.4\%) and of e-cigarette use (Female 5.8\%; Male 6.4\%) than their straight counterparts. Sexual minorities that currently smoke "everyday" (Female AOR 0.26, 95\% CI 0.11-0.63; Male AOR 0.24, 95\% CI 0.01-0.56) or "somedays" (Female AOR 0.28, 95\% CI 0.090.90) had lower adjusted odds of having a complete home smoking compared to those who "never smoked".

Conclusions: Currently smoking everyday was the strongest predictor of not having a complete home smoking ban among sexual minority adults. Focused efforts to increase prevalence of complete home smoking bans should address smoking status to improve health equity among sexual minority adults.

Keywords: Health Disparities, Policy, Survey Research 


\section{Introduction}

Healthy People 2020 tobacco use objectives included increasing the proportion of adults living in smoke-free homes to $87 \%$ and decreasing adult smoking prevalence, a strategy designed to improve the health and wellbeing of sexual minorities ${ }^{1}$. Adoption of voluntary home smoking bans have been influenced by a variety of factors, including public policy smoking restrictions ${ }^{2,3}$. Although banning the use of electronic (e-) cigarettes was not explicitly included in the national smoke-free homes objective, there was a consensus among national and international public health organizations (e.g., the World Health Organization) that smoking bans should also include use of e-cigarettes and vaping ${ }^{4,5}$. Previous research has focused on population prevalence of bans and the relationship of bans with tobacco cessation; however, little is known about how individual level characteristics, such as sexual minority status, smoking status, or use of ecigarettes, may interact with home smoking bans.

Sexual minorities have higher use of all forms of tobacco compared with their straight counterparts $^{6,7,8,9}$. Lifetime prevalence of any tobacco product was the highest among lesbian women $^{8}$. Lesbian and gay adults had statistically significantly higher odds of being a current smoker and an everyday smoker than straight adults ${ }^{10}$. The prevalence of current e-cigarette use followed similar patterns ${ }^{11}$. Furthermore, sexual minority adults report a higher prevalence and higher severity of DSM-5 tobacco use disorder than straight adults ${ }^{7}$.

Examining how smoking bans interact with sexual minority adult smoking status can inform how health policies may be implemented to reduce persistent disparities in tobacco use between lesbian, gay, bisexual, or transsexual (LGBT) adults compared to straight adults ${ }^{5}$. In 2015, the national prevalence of smoke-free homes reached $86.5 \%$, and California exceeded the $87 \%$ goal, with $91.7 \%$ of adults living in smoke-free homes ${ }^{12}$. The prevalence of complete home 
smoking bans among sexual minorities nationally and in California remains unknown, as do the characteristics and correlates of sexual minorities with complete home smoking bans. Thus, the objective of this study is to investigate the relationship between current smoking status and having a complete home smoking ban among sexual minority adults in California, after adjusting for e-cigarette use, socio-demographics, and other characteristics.

\section{Methods}

\section{Study Design}

This secondary data analysis study combined cross-sectional data of the California Behavioral Risk Factor Surveillance System (CA BRFSS), collected in 2014, 2015 and 2016. The CA BRFSS telephone survey of adults was conducted in English and Spanish and used random digit dialing for landline and cell numbers of non-institutional adult populations with geographic stratified sampling and continuous data collection ${ }^{13}$. Respondents with recorded answers for all study variables were included in the present analyses.

\section{Stratification Variables}

Present study analyses were stratified by sex assigned at birth and sexual orientation, using the CA BRFSS dataset variables "Sex," and "Self-Reported Sexual Orientation"13. Sexual minority in this study included participants who identified as lesbian, gay, or bisexual (LGB). In survey years 2014 and 2015, sex was asked as “Are you Male or Female?” In survey year 2016, the question was revised and asked as "Sex Assigned to You at Birth, On Birth Certificate"13. Male and female respondents were analyzed separately to account for intragroup variances.

\section{Predictor Variable}

The categorical variable was "Cigarette Smoking Status," with values 'Currently Smokes (Everyday)', 'Currently Smokes (Somedays)', 'Formerly Smoked', and 'Never Smoked' (reference group) $^{13}$. 


\section{Outcome Variable}

The outcome variable selected from the CA BRFSS datasets was "Smoking Rules in Household” with values 'Completely Prohibited'; 'Generally Prohibited'; 'Allowed in Some Rooms Only'; and 'No Restrictions on Smoking'13. The categorical variable was dichotomized to measure a complete home smoking ban previously defined as no smoking allowed in the home ever. The final variable was labeled "Complete Ban" and the values were 'Yes' and 'No' (reference group).

\section{Covariates}

Covariates included the following: a) e-cigarette use; b) marital status; c) age group; d) educational attainment; e) status of children $(<18)$ in the home; f) income, g) race/ethnicity; and h) survey year. The continuous measure of e-cigarette use in the past 30 days was dichotomized and the final variable was "E-cigarette Use (Past 30 Days)" with values 'Yes' and 'No' (reference group).

\section{Analysis}

Weighted analyses included descriptive, bivariate (i.e., Pearson chi-square, alpha $=0.05$ ), and a multivariable logistic regression. CA BRFSS survey weights reflected estimates from the State of California's Department of Finance ${ }^{13}$. Data management and analyses were conducted with Base SAS version 9.4 (Cary, NC, USA). Waivers were granted by the Institutional Review Boards at both the Oregon Research Institute and Oregon State University, as the dataset was deidentified.

\section{Results}

The final weighted populations in California were sexual minority females $(\mathrm{N}=163,490)$, sexual minority males $(\mathrm{N}=195,746)$, straight females $(\mathrm{N}=3,820,304)$, and straight males 
$(\mathrm{N}=3,841,132)$. Sexual minorities had a lower prevalence of complete home smoking bans $($ Female $=76.2 \%$; Male $=75.7 \%)$ compared to straight adults $($ Female $=83.7 \%$; Male $=78.4 \%)$ Female sexual minorities had the highest prevalence of currently smoking cigarettes everyday (14.5\%) and someday (8.8\%; Figure 1). Male sexual minorities had the highest prevalence of past 30 day e-cigarette use $(6.4 \%)$, followed by female sexual minorities $(5.8 \%)$, straight males $(3.7 \%)$ and straight females $(2.5 \%)$.

Sexual minorities who reported currently smoking cigarettes "everyday" had 75\% lower adjusted odds ratios (AOR) and those who reported currently smoking cigarettes "somedays" had more than $64 \%$ lower AORs of having a home with a complete smoking ban compared to “never" smokers (Table 1). Similarly, female sexual minorities who reported currently smoking “everyday" had 74\% lower AORs and those who reported currently smoking cigarettes "somedays" had $72 \%$ lower AORs of having a home with a complete smoking ban compared to those who "never smoked" (Table 1). Male sexual minorities who reported currently smoking “everyday" had 76\% lower AORs of having a home with a complete smoking ban compared to those who "never smoked" (Table 1).

\section{Discussion}

This is the first paper to investigate home smoking bans among sexual minorities. Prior findings that sexual minorities are more likely to use tobacco products and found that sexual minorities are also less likely to have complete home smoking bans compared to straight adults were extended using CA BRFSS data collected from 2014-2016. Current daily smoking was the strongest predictor of not having a complete home smoking ban among sexual minorities as a group and stratified by sex. Although male sexual minorities reported smoking rates comparable to straight adults, female sexual minorities had highest rate of smoking and male 
sexual minorities had rates of e-cigarette use compared to straight adults.

Higher rates of tobacco use among sexual minorities have been linked to poor mental health and well-being, life dissatisfaction, stressors and discrimination/victimization related to sexual orientation ${ }^{14,15}$. Permissive community norms and nonjudgement towards tobacco use also relate to high rates of use and serve as barriers to cessation attempts ${ }^{16}$. Sexual minority populations often experience a pro-tobacco bar culture that accepts and promotes tobacco use, as well as alcohol use ${ }^{17}$; this also increases environmental smoke and aerosol exposure. Additionally, among same-sex couples, having a partner who was daily or intermittent smoker increased odds of being a smoker ${ }^{18}$.

Our findings have policy implications, especially in conjunction with findings by Wintemberg and colleagues ${ }^{5}$ that sexual gender minority smokers reported greater intention to quit if they lived in a smoke-free community with a smoke free policy active for at least two years compared to a community without a smoke-free policy. Thus, there may be an effect of normative or role-model behavior on smoking.

\section{Limitations}

Study findings are limited to California and may not be generalizable to other states. Living in communities with less LGBT-supportive environmental and community norms could increase the stress and thereby substance use and increase the disparity of home bans ${ }^{14}$. An additional study limitation was that the wording changed for several questions in 2016 that may result in some misclassifications. In survey years 2014 and 2015, sex was asked as "Are you Male or Female," and in 2016 it was changed to "Sex Assigned to You at Birth, On Birth Certificate" ${ }^{\prime 13}$. Similarly, in survey years 2014 and 2015, e-cigarette use was asked as "Past 30 Days, \# Days Used Electronic Cigarettes" but it was expanded in 2016 to "Past 30 Days, \# Days 
Used E-Cig or Vape Pen, Tank, or Mod"13. Thus, prevalence of e-cigarette use may have been underreported prior to 2016.

\section{Conclusion}

Focused efforts to increase prevalence of complete home smoking bans should address smoking status to improve health equity among sexual minority adults. First, expanding and strengthening community resources and social norms for LGB is recommended to improve the well-being of the community and possibly reduce substance use disparities ${ }^{19}$. Second, comprehensive approaches should include implementation of community programs, media interventions, policy and regulation, and tailored surveillance and evaluation. This includes surveillance of tobacco use, targeted outreach and awareness campaigns, access to culturally appropriate tobacco use dependence treatments, and efforts to restrict disproportionate marketing to sexual minority communities by the tobacco industry ${ }^{20}$. Gender and sexual minority inclusion, engagement, and voices should be uplifted in local, state, and national tobacco prevention and control activities. 


\section{Declarations}

\section{Ethics approval and consent to participate}

Waivers were granted by the Institutional Review Boards at both the Oregon Research Institute and Oregon State University, as the dataset was de-identified.

\section{Consent for publication}

Not applicable

\section{Availability of data and materials}

The data that support the findings of this study are available from the Public Health Survey Research Program, California State University, Sacramento but restrictions apply to the availability of these, which were used under license for the current study, and so are not publicly available. Data are however available from the authors upon reasonable request and with permission of the Public Health Survey Research Program, California State University, Sacramento.

\section{Competing interests}

The authors declare that they have no competing interests.

\section{Funding}

None

\section{Authors' contributions}

MCBD analyzed and MCBD, VLI, EW interpreted the survey data regarding the complete home smoking bans. MCBD, VLI, EW were major contributors in writing the manuscript. All authors read and approved the final manuscript.

\section{Acknowledgements}

Not applicable 


\section{References}

1. Office of Disease Prevention and Health Promotion. Tobacco use. Accessed 2 October 2019 from https://www.healthypeople.gov/2020/topics-objectives/topic/tobacco-use/objectives

2. Monson E, Arsenault N. Effects of enactment of legislative (public) smoking bans on voluntary home smoking restrictions: a review. Nicotine Tob Res. 2017;19(2):141-148. doi:10.1093/ntr/ntw171

3. Hovell MF, Adams MA, Hofstetter CR, et al. Complete home smoking bans and antitobacco contingencies: a natural experiment. Nicotine Tob Res. 2014;16(2):186-196. doi:10.1093/ntr/ntt130

4. Wilson N, Hoek J, Thomson G, Edwards R. Should e-cigarette use be included in indoor smoking bans?. Bull World Health Organ. 2017;95(7):540-541. doi:10.2471/BLT.16.186536

5. Wintemberg J, McElroy JA, Ge B, Everett, KD. Can smoke-free policies reduce tobacco use disparities of sexual and gender minorities in Missouri? Nicotine Tob Res. 2017;19(11):1308-1314. doi: 10.1093/ntr/ntx078

6. Hoffman L, Delahanty J, Johnson SE, Zhao X. Sexual and gender minority cigarette smoking disparities: an analysis of 2016 Behavioral Risk Factor Surveillance System data. Prev Med. 2018;113:109-115. doi:10.1016/j.ypmed.2018.05.014

7. McCabe SE, Matthews AK, Lee JGL, Veliz P, Hughes TL, Boyd CJ. Tobacco use and sexual orientation in a national cross-sectional study: age, race/ethnicity, and sexual identityattraction differences. Am J Prev Med. 2018;54(6):736-745.

doi:10.1016/j.amepre.2018.03.009 
8. Wheldon CW, Kaufman AR, Kasza KA, Moser RP. Tobacco use among adults by sexual orientation: findings from the population assessment of tobacco and health study [published correction appears in LGBT Health. 2020 Jul;7(5):277]. LGBT Health. 2018;5(1):33-44. doi:10.1089/lgbt.2017.0175

9. Wang TW, Asman K, Gentzke AS, et al. Tobacco product use among adults — United States, 2017. MMWR Morb Mortal Wkly Rep. 2018;67:1225-1232. doi: 10.15585/mmwr.mm6744a2

10. Azagba S, Shan L, Latham K, Qeadan F. Disparities in adult cigarette smoking and smokeless tobacco use by sexual identity. Drug Alcohol Depend. 2020;206:107684. doi:10.1016/j.drugalcdep.2019.107684

11. Al Rifai M, Mirbolouk M, Jia X, et al. E-cigarette use and risk behaviors among lesbian, gay, bisexual, and transgender adults: the Behavioral Risk Factor Surveillance System (BRFSS) survey. Kans J Med. 2020;13:318-321. doi:10.17161/kjm.vol13.13861

12. Office of Disease Prevention and Health Promotion. Tobacco use: TU-14 increase the proportion of smoke-free homes. Accessed 2 October 2019 from https://www.healthypeople.gov/2020/data-search/Search-the-Data\#objid=5318

13. Tomassilli JC, Bryant SM. California Behavioral Risk Factor Surveillance System (BRFSS) SAS dataset documentation and technical report: 1984-2016. Public Health Survey Research Program, California State University, Sacramento.

14. Gordon AR, Fish JN, Kiekens WJ, Lightfoot M, Frost DM, Russell ST. Cigarette smoking and minority stress across age cohorts in a national sample of sexual minorities: results from the generations study. Ann Behav Med. 2021;55(6):530-542. 
doi:10.1093/abm/kaaa079

15. McCabe SE, Hughes TL, Matthews AK, et al. Sexual orientation discrimination and tobacco use disparities in the United States. Nicotine Tob Res. 2019;21(4):523-531. doi:10.1093/ntr/ntx283

16. Hinds JT, Loukas A, Perry CL. Explaining sexual minority young adult cigarette smoking disparities. Psychol Addict Behav. 2019;33(4):371-381. doi:10.1037/adb0000465

17. Matthews AK, Cesario J, Ruiz R, Ross N, King A. A qualitative study of the barriers to and facilitators of smoking cessation among lesbian, gay, bisexual, and transgender smokers who are interested in quitting. LGBT Health. 2017;4(1):24-33. doi:10.1089/lgbt.2016.0059

18. Gamarel KE, Mitchell JW. Comparisons between smoking patterns among sexual minority females and males in romantic relationships. Health Educ Behav. 2019;46(1):176-184. doi:10.1177/1090198118757821

19. Eisenberg ME, Erickson DJ, Gower AL, et al. Supportive community resources are associated with lower risk of substance use among lesbian, gay, bisexual, and questioning adolescents in Minnesota. J Youth Adolesc. 2020;49(4):836-848. doi:10.1007/s10964019-01100-4

20. Matthews PA, Blok AC, Lee JGL, et al. SBM recommends policy support to reduce smoking disparities for sexual and gender minorities [published correction appears in Transl Behav Med. 2019 Mar 1;9(2):397]. Transl Behav Med. 2018;8(5):692-695. doi:10.1093/tbm/ibx017 
Figures

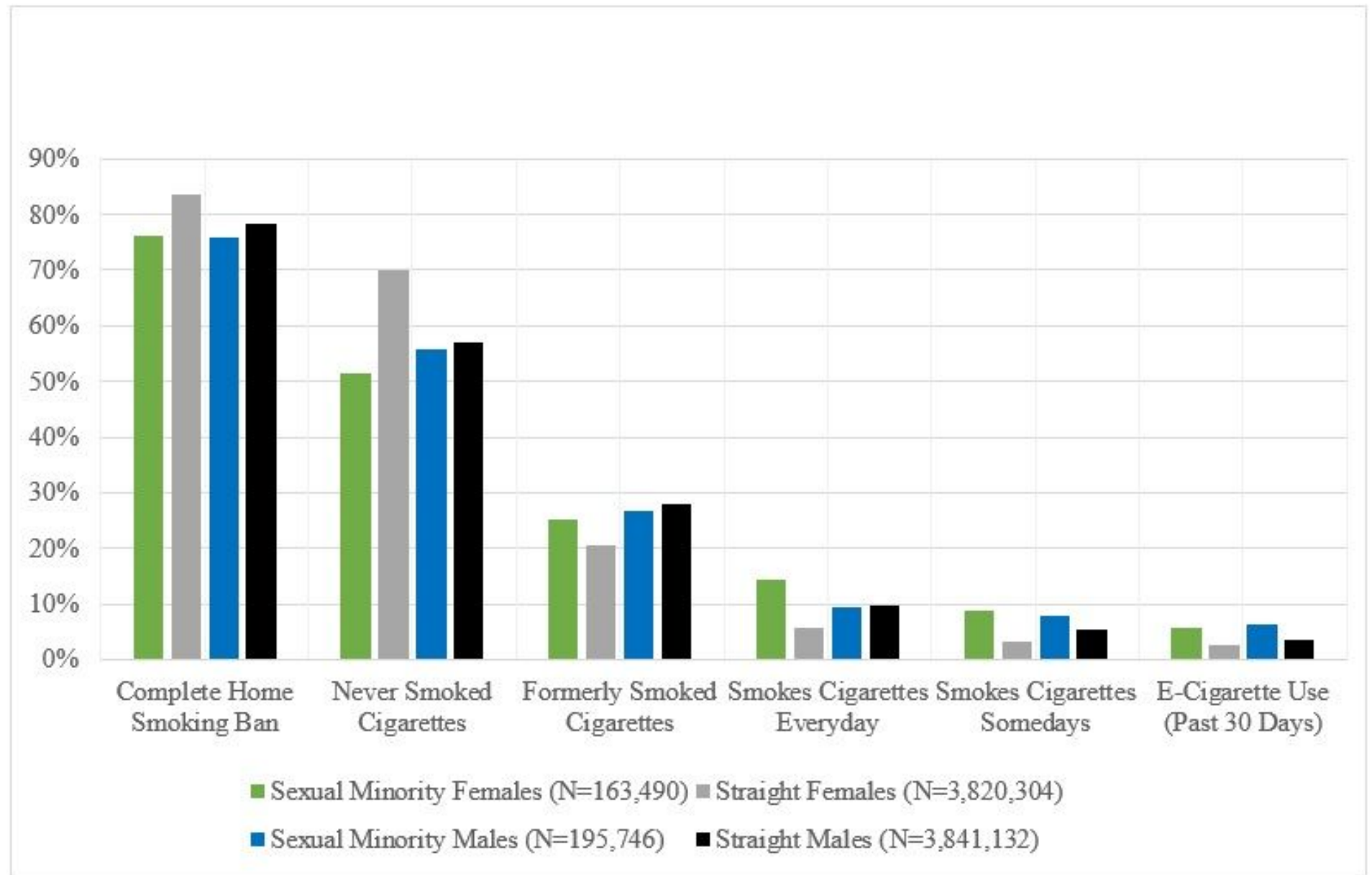

\section{Figure 1}

Complete Home Smoking Ban, Smoking Status, and E-Cigarette Use: Weighted Adult Prevelance, CA BRFSS, 2014-2016 